\title{
REFERENCE
}

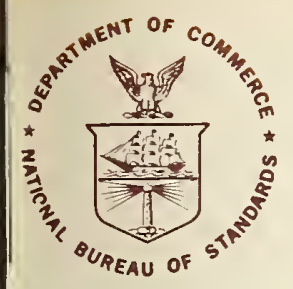

NBS TECHNICAL NOTE 844

U.S. DEPARTMENT OF COMMERCE / National Bureau of Standards

\section{Designs for the Calfbration of Small Groups of Standards in the Presence of Drift}

\section{- QC - 100 .45753 no. 844 1974}




\section{NATIONAL BUREAU OF STANDARDS}

The National Bureau of Standards ${ }^{1}$ was established by an act of Congress March 3, 1901. The Bureau's overall goal is to strengthen and advance the Nation's science and technology and facilitate their effective application for public befiefit. To this end, the Bureau conducts research and provides: (1) a basis for the Nation's physical measurement system, (2) scientific and technological services for industry and government, (3) a technical basis for equity in trade, and (4) technical services to promote public safety. The Bureau consists of the Institute for Basic Standards, the Institute for Materials Research, the Institute for Applied Technology, the Institute for Computer Sciences and Technology, and the Office for Information Programs.

THE INSTITUTE FOR BASIC STANDARDS provides the central basis within the United States of a complete and consistent system of physical measurement; coordinates that system with measurement systems of other nations; and furnishes essential services leading to accurate and uniform physical measurements throughout the Nation's scientific community, industry, and commerce. The Institute consists of a Center for Radiation Research, an Office of Measurement Services and the following divisions:

Applied Mathematics - Electricity - Mechanics - Heat - Optical Physics — Nuclear Sciences $^{2}$ - Applied Radiation ${ }^{2}$ - Quantum Electronics ${ }^{3}$ - Electromagnetics ${ }^{3}$ - Time and Frequency ${ }^{3}$ - Laboratory Astrophysics ${ }^{3}$ - Cryogenics ${ }^{3}$.

THE INSTITUTE FOR MATERIALS RESEARCH conducts materials research leading to improved methods of measurement, standards, and data on the properties of well-characterized materials needed by industry, commerce, educational institutions, and Government; provides advisory and research services to other Government agencies; and develops, produces, and distributes standard reference materials. The Institute consists of the Office of Standard Reference Materials and the following divisions:

Analytical Chemistry - Polymers - Metallurgy - Inorganic Materials — Reactor

Radiation - Physical Chemistry.

THE INSTITUTE FOR APPLIED TECHNOLOGY provides technical services to promote the use of available technology and to facilitate technological innovation in industry and Government; cooperates with public and private organizations leading to the development of technological standards (including mandatory safety standards), codes and methods of test; and provides technical advice and services to Government agencies upon request. The Institute consists of a Center for Building Technology and the following divisions and offices:

Engineering and Product Standards - Weights and Measures - Invention and Innovation - Product Evaluation Technology - Electronic Technology - Technical Analysis - Measurement Engineering - Structures, Materials, and Life Safety ${ }^{\text {* }}$ - Building Environment * Technical Evaluation and Application ${ }^{4}$ — Fire Technology.

THE INSTITUTE FOR COMPUTER SCIENCES AND TECHNOLOGY conducts research and provides technical services designed to aid Government agencies in improving cost effectiveness in the conduct of their programs through the selection, acquisition, and effective utilization of automatic data processing equipment; and serves as the principal focus within the executive branch for the development of Federal standards for automatic data processing equipment, techniques, and computer languages. The Institute consists of the following divisions:

Computer Services - Systems and Software - Computer Systems Engineering - Information Technology.

THE OFFICE FOR INFORMATION PROGRAMS promotes optimum dissemination and accessibility of scientific information generated within NBS and other agencies of the Federal Government; promotes the development of the National Standard Reference Data System and a system of information analysis centers dealing with the broader aspects of the National Measurement System; provides appropriate services to ensure that the NBS staff has optimum accessibility to the scientific information of the world. The Office consists of the following organizational units:

Office of Standard Reference Data - Office of Information Activities - Office of Technical Publications - Library - Office of International Relations.

1 Headquarters and Laboratories at Gaithersburg. Maryland, unless otherwise noted; mailing addrem Washington, D.C. 20234

Part of the Center for Radiation Research.

Located at Boulder, Colorado 80302 .

4 Part of the Center for Building Technology. 
Joseph M. Cameron and Geraldine E. Hailes

The process of calibrating a small number of "unknown" standards relative to one or two reference standards involved determining differences among the group of objects. Drift, due most often to temperature effects, or a "left-right" polarity effect can bias both the values assigned to the objects and the estimate of the effect of random errors. This note presents schedules of measurements of differences that eliminate the bias from these sources in the assigned value and variances and at the same time gives estimates of the magnitude of these extraneous components. The use of these designs in measurement process control is discussed and a computer program in BASIC is presented.

Key Words: Calibration; calibration design; experiment design; instrumental drift; measurement process; statistical analysis; trend elimination

\section{Introduction}

In very few processes can the effect of time be ignored. Instability in the object being measured, inability to maintain constant conditions or procedures, and variations in the detector or comparator all contribute to changes with time. A number of approaches have been suggested for reducing or eliminating the effects of these temporal effects on the validity of one's measurements. One way is to make measurements far enough apart in time (usually with some formal randomization procedure to guarantee statistical independence of the measurements) that the cumulative effects from the various sources appear in the random error component. At the other extreme, one can go to great lengths to eliminate these time dependent effects by achieving better environmental control, better instruments, better procedures, etc. If the measurements are to be transferred, as with instrument calibrations, then the first procedure leads to error bounds in which the random error limits include a between-time component whereas the latter procedure suppresses such a component. Neither of these represent the conditions of use adequately. 
A compromise consists of arranging the experiment under its normal conditions so that it is as nearly as possible free of time dependent effects. The classic example of this is afforded by the calibration of thermometers in a bath with a gradually rising temperature using the schedule whose structure is as follows for a standard $\mathrm{s}$, and 4 unknowns, $\mathrm{T}_{1}, \mathrm{~T}_{2}, \mathrm{~T}_{3}, \mathrm{~T}_{4}$

$$
\mathrm{S}_{1} \mathrm{~T}_{2} \mathrm{~T}_{3} \mathrm{~T}_{4} \mathrm{~S} \mathrm{~T}_{4} \mathrm{~T}_{3} \mathrm{~T}_{2} \mathrm{~T}_{1} \mathrm{~S}
$$

If the measurements are evenly spread in time, then the average of the bath temperature for all thermometers are the same (see [ 3 ] for a discussion of this practice). A similar procedure has been followed in weighing where in the substitution method one measures in scale units

$$
A, B, B+S, A+S
$$

to obtain the differtnce $A-B$ and the deflection corresponding to the sensitivity weight, $\mathrm{S}$.

The calibration of a small number of "unknown" objects relative to one or two reference standards involves determining differences among

the group of objects. Instrumental drift, due most often to temperature effects, or a "left-right" polarity effect can bias both the values assigned to the objects and the estimate of the effect of random errors. This note presents schedules of measurements of differences that eliminate the bias from these sources and at the same time gives estimates of the magnitude of these extraneous components. The use of these designs in measurement process control is discussed and a computer program in BASIC is presented in this report. 
A single isolated measurement, like a single event in history, is difficult to interpret unless it can be regarded as a part of a continuing process. When the measurement is looked upon as the output of a process-a production process whose output is the measured values--then one can attribute to the single measurement the properties of the process from which it arose (for a discussion of this approach, see Eisenhart [ 2 ]). Just as with any production process, the operating characteristics are determined by building some redundancy into the system. Redundancy is needed to assure oneself that he has indeed measured the sought after quantity, uncontaminated by extraneous factors related to the operator, instrument, environment, or other items.

Among the characteristics of the process are these associated with the ability to repeat a measurement both in the sho $t$ term and in the long term. Repetitions made within a few hours, such as with designs having more observations than unknowns, usually exhibit less variation than those made at long time intervals. This additional long-term component of variance can be measured from the agreement among repeated measurements on the same quantity. In addition to these properties related to variability, one needs to incorporate checks on the systematic errors which may possibly affect the process, and, if possible, measurements that provide information as to the adequacy of the assumptions in the underlying physical model.

In calibration it is often convenient to measure a check standard along with the calibration of one or more unknowns. One thus has a value for monitoring the process that is on an equal footing with the unknowns. By tracking its long-run performance, one can determine not only the presence of components of variance, but also by recording ancillary information on environmental and other factors one can develop information for assessing the adequacy of the assumed physical model and for setting bounds to the effect from known sources of possible systematic error. This "check standard" need not be the value of a single item but may take the form of a difference between two such items or some linear combination of several.

The effect of some sources of systematic error can be eliminated by "balancing out" the effect by repeating the measurement of a difference, $(x-y)$ in the reverse order, $(y-x)$. Time dependent effects can be balanced out by using the techniques of this report. For others, it is sometimes possible to alter the conditions to levels of a factor beyond that known to have been in effect at the time of the measurement and to use the changes produced in the output at these extremes as a bounds to the effect of the factor.

In all cases one has to continually monitor the process output just as one does with an industrial production process if he is to have assurance that the calibrations are correct. 
3. Substitution Weighing

Consider first the simple situation of scale deflections produced on a balance by adding weights $A$ and $B$ and a sensitivity weight $S$. One could use either of the following sequences.

$\begin{array}{cc}\text { Sequence I } & \frac{\text { Sequence 2 }}{\mathrm{A}} \\ \mathrm{A}+\mathrm{S} & \mathrm{A} \\ \mathrm{B} & \mathrm{B}+\mathrm{S} \\ \mathrm{B}+\mathrm{S} & \mathrm{A}+\mathrm{S}\end{array}$

In high precision wors one invariably finds a change in balance response with time so that the value for the difference (A-B) will obviously be contaminated by whatever time effects exist for Sequence 1 . If Sequence 2 is used, it may be represented as follows.

$\begin{array}{ccc}\text { Quantity } & \text { Effect of Drift } & \frac{\text { Scale Divisions }}{A} \\ B & -3 \Delta & \mathrm{x}_{1} \\ \mathrm{~B}+\mathrm{S} & \Delta & \mathrm{x}_{2} \\ \mathrm{~A}+\mathrm{S} & 3 \Delta & \mathrm{x}_{3}\end{array}$

and the quantity

$$
\frac{1}{2}\left(x_{1}-x_{2}-x_{3}+x_{4}\right)
$$

can be seen to give an unbiased value for ( $A-B$ ) because the drift effect ( $a)$ change in scale reading between each observation) cancels out. The least squares values for $A-B, S$, and $\Delta$ in scale divisions are

$$
\begin{aligned}
(\hat{A-B}) & =\frac{1}{2}\left(x_{1}-x_{2}-x_{3}+x_{4}\right) \\
\hat{S} & =\frac{1}{2}\left(x_{1}-3 x_{2}+3 x_{3}-x_{4}\right) \\
\hat{\Delta} & =\frac{1}{4}\left(-x_{1}+x_{2}-x_{3}+x_{4}\right)
\end{aligned}
$$


At NBS, the calibration of liquid in glass thermometers is usually carried out in a controlled bath which is continually heated so as to give a slight temperature increase with time. The temperature of the bath is measured by resistance thermometry at the start, middle, and end of the run with the test thermometers being run once each in the first interval and once again in reverse order in the second. The time sequence for the resistance measurements $R_{1}, R_{2}, R_{3}$ and the two series of test thermometer values denoted by $\mathrm{T}_{1} \mathrm{~T}_{2} \cdot \cdot \mathrm{T}_{\mathrm{k}}$ are as follows:

$$
\mathrm{R}_{1} \mathrm{~T}_{1} \mathrm{~T}_{2} \cdot \cdots \mathrm{T}_{\mathrm{k}} \mathrm{R}_{2} \mathrm{~T}_{\mathrm{k}}^{\prime} \cdot \cdots \mathrm{T}_{2}^{\prime} \mathrm{T}_{1}^{\prime} \mathrm{R}_{3}
$$

If equal time intervals are maintained between readings of the test thermometers, then one would expect an increase, $\Delta \mathrm{T}$ in temperature with each interval except perhaps the middle one in which the resistance thermometer reading, $R_{2}$, is made. The analysis of this form of data is given in Appendix A.

\section{Polarimeter Data}

In determining the optical rotation of a quartz control plate used as reference standards in polarimeters, one measures the voltage response of a synchronous detector as the angle is varied. However, the response, $y$, of the system has a nearly linear drift with the angle so that one can represent this drift effect relative to the centroid of the data as being either - $\cdot-3 \Delta,-2 \Delta,-\Delta, 0, \Delta, 2 \Delta, 3 \Delta, \cdot \cdot$ with $\Delta$ being the increment to the response added in each time interval. [For even $\mathrm{n}$ it is convenient to use . $\cdot-3 \Delta,-\Delta, \Delta, 3 \Delta \cdot \cdot$ or $2 \Delta$ increment per time interval.]

In the polarimeter experiment the response is a linear function of angle so that the observation becomes

$$
y_{i}=\alpha+\beta x_{i}+\left(i-\frac{n+l}{2}\right) \Delta+\text { random error }
$$

where the $x_{i}$ are evenly spaced deviations from the nominal angle, e.g., $x=0 ", 10 ", 20 ", 30 ", \cdot-\cdot$ If the usual estimate of $\alpha$ and $\beta$ are to remain unbiased and unchanged in precision, then one must have

$$
\sum x_{i}\left(i-\frac{n+1}{2}\right)=0
$$

so that the estimates are orthogonal to the drift in the detector. The following orderings have this property: 


\begin{tabular}{|c|c|c|c|c|}
\hline \multirow[b]{2}{*}{$\begin{array}{c}\text { Measurement } \\
\text { Number }\end{array}$} & \multicolumn{2}{|c|}{$n=4$} & \multicolumn{2}{|c|}{$\mathrm{n}=5$} \\
\hline & $\begin{array}{l}\text { Quantity to } \\
\text { be Measured }\end{array}$ & $\begin{array}{l}\text { Setting for } \\
\text { Polarimeter } \\
\end{array}$ & $\begin{array}{l}\text { Quantity to } \\
\text { be Measured }\end{array}$ & $\begin{array}{l}\text { Setting for } \\
\text { Polarimeter }\end{array}$ \\
\hline 1 & $\alpha+2 \beta$ & $20 "$ & $\alpha+\beta$ & $10 "$ \\
\hline 2 & $\alpha$ & O" & $\alpha+4 \beta$ & $40^{\prime \prime}$ \\
\hline 3 & $\alpha+3 \beta$ & $30^{\prime \prime}$ & $\alpha+2 \beta$ & $20 "$ \\
\hline 4 & $\alpha+\beta$ & $10^{\prime \prime}$ & $\alpha$ & O" \\
\hline 5 & --- & --- & $\alpha+3 \beta$ & $30 "$ \\
\hline
\end{tabular}


6. Calibration Designs

The term calibration design has been applied [ 1 ] to experiments where only differences between nominally equal objects or groups of objects can be measured. Perhaps the simplest such experiment consists in measuring the differences between the two objects of the $n(n-1) / 2$ distinct pairing that can be formed from $n$ objects. Ordinarily the order in which these measurements are made is of no consequence. However, when the response of the comparator is time dependent, attention to the order is important if one wishes to minimize the effect of these changes. When this effect can be adequately represented by a linear drift, it is possible to balance out the effect by proper ordering of the observations. As with the polarimeter data, this drift can be represented by the series . . $-3 \Delta,-2 \Delta,-\Delta, 0, \Delta, 2 \Delta, 3 \Delta, \cdot$. . if $\mathrm{n}(\mathrm{n}-1) / 2$ is odd or by $\cdot .-5 \Delta,-3 \Delta,-\Delta, \Delta, 3 \Delta, 5 \Delta$.. . if $\mathrm{n}(\mathrm{n}-1) / 2$ is even.

For $n=4, n(n-1) / 2=6$, and it turns out that it is not possible to balance out the drift effect with 6 measurements. However, with 8 measurements the balance can be achieved by the following order, denoting the four objects by A, B, C, D.

\begin{tabular}{|c|c|c|c|c|c|}
\hline Observation & Observatio & $n i$ & s a & $\mathrm{Me}$ & asur \\
\hline & $\underline{A}$ & $\underline{B}$ & $\underline{c}$ & $\underline{\mathrm{D}}$ & $\Delta$ \\
\hline $\mathrm{Y}_{1}$ & + & - & 0 & 0 & -7 \\
\hline $\mathrm{y}_{2}$ & - & 0 & 0 & + & -5 \\
\hline $\mathrm{y}_{3}$ & 0 & 0 & + & - & -3 \\
\hline $\mathrm{y}_{4}$ & 0 & + & - & 0 & -1 \\
\hline $\mathrm{y}_{5}$ & 0 & + & 0 & - & 1 \\
\hline $\mathrm{y}_{6}$ & - & 0 & 0 & + & 3 \\
\hline $\mathrm{y}_{7}$ & + & 0 & - & 0 & 5 \\
\hline $\mathrm{y}_{8}$ & 0 & - & + & 0 & 7 \\
\hline
\end{tabular}

The notation used here, the plus and minus signs, indicate the items. entering into the difference measurement. Thus, $y_{2}$ is a measurement of the difference (D-A).

To see how the drift effect is balanced out, consider item $\mathrm{C}$ which occurs in the third, fourth, seventh, and eighth observations. In the third and eighth observations the item occurs positively and the corresponding drift effects are $-3 \Delta$ and $7 \Delta$ respectively. For the fourth and seventh observations, item $C$ occurs negatively while the corresponding 
drift effects are $-\Delta$ and $5 \Delta$. The overall effect can be represented by the sum of cross products of the columns for $C$ and $\Delta$, namely

$$
[1](-3 \Delta)+[-1](-\Delta)+[-1](5 \Delta)+[1](7 \Delta)=0
$$

using square brackets to denote the coefficient attached to the direction of the difference and parenthesis for the drift effect. For $A$, one has

$$
[1](-7 \Delta)+[-1](-5 \Delta)+[-1](3 \Delta)+[1](5 \Delta)=0
$$

In general, if the cross products sum out to zero, then the drift effect is said to be completely "balanced out" or "orthogonal" to the items being measured.

\section{Restraints}

In calibration designs only differences between items are measured so that unless one or more of them are standards for which values are known, one cannot assign values for the remaining "unknown" items. Algebraically, one has a system of equations that is not of full rank and needs the value for one item or the sum of several items as the restraint to lead to a unique solution.

In the design of Section 6 , for example, if one has a single standard and three unknowns, the standard can be assigned to any one of the letters. (The same would be true of three standards and one unknown.) If there are two standards and two unknowns, the choice of which pair of letters to assign for the standards is important in terms of minimizing the uncertainty in the unknown.

It turns out that the pairing of $A$ with $D$ or of $B$ with $C$ is slightly less efficient (see Appendix B) than the other pairings A with B or C with $D$. This results from the fact that the observation on the differences $(A-D)$ and $(B-C)$ are repeated and it is usually better (to achieve smaller variance for the test items) to measure differences between standards and unknowns than between pairs of standards. 
8. Use of Calibration Design in Gage Block Calibration

The calibration design of Section 6 is used in gage block calibration at the National Bureau of Standards and the analysis and interpretation of the design for this application is representative of the principles involves in the use of the design in other applications.

At NBS two master sets of gage blocks are maintained for transferring length calibration to users gage blocks, these are designated $A$ and $B$ and their sum is designated by $K$. These are combined with two sets of unknowns, designated $C$ and $D$. The difference (A-B) is used as the check standard.

If we denote the values determined for $A B C$ and $D$ by $\hat{A} \hat{B} \hat{C} \hat{D}$ in accordance with the statisticians'practice of distinguishing the value from the experiment from the sought-after or long-run value, we may then write

$$
\begin{aligned}
\hat{A} & =\frac{1}{24}\left(5 y_{1}-2 y_{2}-y_{3}-2 y_{4}-3 y_{5}-2 y_{6}+3 y_{7}+2 y_{8}\right)+\frac{K}{2} \\
\hat{B} & =\frac{1}{24}\left(-5 y_{1}+2 y_{2}+y_{3}+2 y_{4}+3 y_{5}+2 y_{6}-3 y_{7}-2 y_{8}\right)+\frac{K}{2} \\
\hat{A-B} & =\frac{1}{24}\left(10 y_{1}-4 y_{2}-2 y_{3}-4 y_{4}-6 y_{5}-4 y_{6}+6 y_{7}+4 y_{8}\right) \\
\hat{C} & =\frac{1}{24}\left(-y_{1}+2 y_{2}+5 y_{3}-6 y_{4}-y_{5}+2 y_{6}-7 y_{7}+6 y_{8}\right)+\frac{K}{2} \\
\hat{D} & =\frac{1}{24}\left(y_{1}+6 y_{2}-5 y_{3}-2 y_{4}-7 y_{5}+6 y_{6}-y_{7}+2 y_{8}\right)+\frac{K}{2}
\end{aligned}
$$

where $\hat{A}+\hat{B}$ necessarily sum to $K$.

These values have the following standard deviations in terms of the long run precision as represented by the process standard deviation $\sigma$.

$$
\begin{aligned}
& \text { s.d. }(\hat{A})=s \cdot d \cdot(\hat{B})=\sigma \sqrt{\frac{5}{48}} \\
& \text { s.d. }(\hat{A-B})=\sigma \sqrt{\frac{5}{12}} \\
& \text { s.d. }(\hat{C})=s \cdot d \cdot(\hat{D})=\sigma \sqrt{\frac{13}{48}}
\end{aligned}
$$

One also obtains values $\hat{\Delta}$ for $\Delta$ where

$$
\begin{gathered}
\hat{\Delta}=\frac{1}{168}\left(-7 y_{1}-5 y_{2}-3 y_{3}-y_{4}+y_{5}+3 y_{6}+5 y_{7}+7 y_{8}\right) \\
\text { s.d. }(\hat{\Delta})=\sigma \sqrt{168}
\end{gathered}
$$


Because this is an overdetermined system (more observations than unknowns) the deviation between observed and computed value is, in general, different from zero and reflects the random errors of measurement. These deviations, $d_{1} d_{2} \cdot \cdot d_{8}$ are as follows:

$$
\begin{aligned}
& \mathrm{d}_{1}=\frac{1}{168}\left(49 y_{1}-7 y_{2}-7 y_{3}+21 y_{4}+49 y_{5}+49 y_{6}-7 y_{7}+21 y_{8}\right) \\
& a_{2}=\frac{1}{168}\left(-7 y_{1}+87 y_{2}+13 y_{3}-5 y_{4}+33 y_{5}-41 y_{6}+53 y_{7}+35 y_{8}\right) \\
& d_{3}=\frac{1}{168}\left(-7 y_{1}+13 y_{2}+89 y_{3}+25 y_{4}-39 y_{5}+37 y_{6}+57 y_{7}-7 y_{8}\right) \\
& d_{4}=\frac{1}{168}\left(21 y_{1}-5 y_{2}+25 y_{3}+11 y_{4}-27 y_{5}+3 y_{6}-23 y_{7}+63 y_{8}\right) \\
& d_{5}=\frac{1}{168}\left(49 y_{1}+33 y_{2}-39 y_{3}-27 y_{4}+97 y_{5}+25 y_{6}+9 y_{7}+21 y_{8}\right) \\
& d_{6}=\frac{1}{168}\left(49 y_{1}-41 y_{2}+37 y_{3}+3 y_{4}+25 y_{5}+103 y_{6}+13 y_{7}-21 y_{8}\right) \\
& d_{7}=\frac{1}{168}\left(-7 y_{1}+53 y_{2}+57 y_{3}-23 y_{4}+9 y_{5}+13 y_{6}+73 y_{7}-7 y_{8}\right) \\
& d_{8}=\frac{1}{168}\left(21 y_{1}+35 y_{2}-7 y_{3}+63 y_{4}+21 y_{5}-21 y_{6}-7 y_{7}+63 y_{8}\right)
\end{aligned}
$$

These deviations provide the information needed to obtain a value, s, which is the experiment's value for the process standard deviation, $\sigma$.

$$
s=\sqrt{\frac{\sum(\mathrm{dev})^{2}}{4}} \quad \text { degrees of freedom }=4
$$

The number of degrees of freedom results from taking the number of observations less the number of unknowns then adding one (for the restraint) to give $8-5+1=4$. 
9. Example

Routine calibration of gage blocks is carried out with two NBS master blocks (designated S. and S..) and two test blocks (designated $\mathrm{X}$ and $\mathrm{Y}$ ). The blocks are placed close together on a metal platen for a sufficiently long time to insure temperature equilibrium. A mechanical intercomparator is used to determine the difference between the blocks by first determining a reading for the block indicated by "+" then following with the block indicated by "-". The difference between these two readings is the observation, $y$ (all values are in micro-inch). For a set of 0.101 in blocks, the following data was obtained.

DATA FROM NBS CALIBRATION OF FOUR 0.101 INCH GAGE BLOCKS

\begin{tabular}{|c|c|c|c|c|c|c|}
\hline$\underline{i}$ & Schedule & $\begin{array}{c}\text { Difference } \\
\text { Measured } \\
\end{array}$ & $\begin{array}{c}\text { First } \\
\text { Reading } \\
\end{array}$ & $\begin{array}{l}\text { Second } \\
\text { Reading } \\
\end{array}$ & $\begin{array}{c}\text { Difference } \\
y(i) \\
\end{array}$ & Deviation \\
\hline 1 & +-00 & S. - S.. & 52.0 & 52.5 & -0.5 & 0.029 \\
\hline 2 & $-00+$ & $\mathrm{Y}-\mathrm{S}$. & 45.2 & 52.1 & -6.9 & -0.046 \\
\hline 3 & $00+-$ & $X-Y$ & 50.0 & 45.1 & 4.9 & 0.113 \\
\hline 4 & $0+-0$ & S... $-\mathrm{X}$ & 53.1 & 50.0 & 3.1 & 0.571 \\
\hline 5 & $0+0-$ & S.. $-Y$ & 52.3 & 45.2 & 7.1 & -0.238 \\
\hline 6 & $-00+$ & $Y-S$ & 45.1 & 52.0 & -6.9 & -0.079 \\
\hline 7 & $+0-0$ & S. $-x$ & 52.0 & 50.1 & 1.9 & -0.154 \\
\hline 8 & $0-+0$ & S.. $-\mathrm{x}$ & 50.1 & 52.3 & -2.2 & 0.304 \\
\hline
\end{tabular}

S.+S.. $=6.4$ used as restraint

S. S.. = -0.133 used as check standard

$\sigma=.32$ accepted standard deviation

The values for the blocks and the drift effect, $\Delta$, are

$$
\begin{aligned}
\hat{S} .= & \frac{1}{24}[5(-0.5)-2(-6.9)-(4.9)-2(3.1)-3(7.1)-2(-6.9)+3(1.9)+ \\
& 2(-2.2)]+\frac{(6.4)}{2} \\
= & \frac{1}{24}(-6.0)+3.2=2.9500 \\
\hat{\mathrm{S} .}= & \frac{1}{24}[-5(-0.5)+2(-6.9)+(4.9)+2(3.1)+3(7.1)+2(-6.9)-3(1.9)- \\
& 2(-2.2)]+\frac{(6.4)}{2} \\
= & \frac{1}{24}(6.0)+3.2=3.4500
\end{aligned}
$$




$$
\begin{aligned}
\hat{S .} . & S=-0.5 \\
\hat{\mathrm{X}}= & \frac{1}{24}[-(-0.5)+2(-6.9)+5(4.9)-6(3.1)-(7.1)+2(-6.9)-7(1.9)+ \\
& 6(-2.2)]+\frac{(6.4)}{2} \\
= & \frac{1}{24}(-54.8)+3.2=0.9167 \\
\hat{\mathrm{Y}}= & \frac{1}{24}[(-0.5)+6(-6.9)-5(4.9)-2(3.1)-7(7.1)+6(-6.9)-(1.9)+ \\
& 2(-2.2)]+\frac{(6.4)}{2} \\
= & \frac{1}{24}(-170.0)+3.2=-3.8833 \\
\hat{\Delta}= & \frac{1}{168}[-7(-0.5)-5(-6.9)-3(-4.9)-1(3.1)+(7.1)+3(-6.9)+5(1.9)+ \\
& 7(-2.27) \\
= & \frac{1}{168}(.7)=0.0042
\end{aligned}
$$

The accepted standard deviation for the process is $0.32 \mu$-in so that one can compare the observed standard deviation, s,

$$
s=\sqrt{\sum \mathrm{dev}^{2} / 4}=\sqrt{\frac{.5208}{4}}=0.361
$$

to the accepted value by computing

$$
F=\left(\frac{s}{\sigma}\right)^{2}=\frac{0.1302}{0.1024}=1.27
$$

Had the ratio $(\mathrm{s} / \sigma)^{2}$ exceeded 3.32 (the critical value for the $1 \%$ probability level of the $F$ distribution), then the measurements would be regarded as being "out of control" and would be repeated. The other check on process performance is provided by the check standard for which the difference between (S.-S..) and its accepted value should be less than 3 times the standard deviation of (S.-S..). See Section 10 for a discussion of this test.

The drift term, $\hat{\Delta}$, has a standard deviation of $\sigma / \sqrt{ } 168$ or 0.025 . The statistical significance of $\hat{\Delta}$ can be judged by forming the ratio $\frac{\hat{\Delta}}{\sigma / \sqrt{168}}$.

If this ratio exceeds 3 , then $\hat{\Delta}$ would be regarded as significant. However, because the design has eliminated the effect of drift on the 
yalues of the blocks, one would not be concerned about a "significant" $\widehat{\Delta}$ unless it was greatly in excess of previously encountered values.

The deviations are computed as shown in section 8, for example, for the deviation corresponding to $y_{8}$ is given by

$$
\begin{aligned}
(\mathrm{dev})_{8}= & \frac{1}{168}[21(-0.5)+35(-6.9)-7(4.9)+63(3.1)+21(7.1)-21(-6.9)- \\
& 7(1.9)+63(-2.2)] \\
= & \frac{1}{168}[51.1]=0.304
\end{aligned}
$$




\section{Process Control}

As mentioned in Section 2, continued monitoring of the measurement process is required to assure that predictions based on the accepted values for process parameters are still valid. For gage block calibration, the process is monitored for precision by comparison of the observed standard deviation to the accepted value, $\sigma_{w}$, by means of the F-test. In the case of the design of section 6 , the square of the ratio of the two standard deviations is compared to the critical value, $F(4, \infty, \alpha)$, which is the $\alpha$ probability point of the $F$ distribution for degrees of freedom 4 and $\infty$. [For calibrations at NBS, $\alpha$ is chosen as .01 to give $F(4, \infty, .01)=3.32]$.

The check for systematic error is given by comparison of the observed value of the difference, S. - S.., between the two standards with its accepted value. The uncertainty of this difference is given by $\sigma_{\mathrm{T}}=\sqrt{(5 / 12) \sigma_{\mathrm{W}}^{2}+\sigma_{\mathrm{B}}^{2}}$ where $\sigma_{\mathrm{W}}$ is the "within run" standard deviation and $\sigma_{B}$ is the component of variance arising from variations from run-torun. The value of $\sigma_{\mathrm{T}}$ is obtained directly from the sequence of values of S. - S.. arising in regular calibrations. The check standard test is therefore,

$$
t=\frac{\operatorname{lobserved}\left(S_{.}-S_{. .}\right)-\operatorname{accepted}\left(S_{.}-S_{.}\right) \mid}{\sigma_{T}}<3
$$

i.e., $t$ is compared to the critical value 3.0 which would correspond to the .003 probability level for the normal distribution.

If both the "precision" (F-test) and "accuracy" (t-test) criteria are satisfied, the process is regarded as being "in control" and values for the unknowns, $X$ and $Y$, and their associated uncertainties are regarded as valid. Failure on either criterion is an "out-of-control" signal and the measurements are repeated.

When the between run component, $\sigma_{B}$, is present, the standard deviation associated with the values for the unknowns are given by

$$
\begin{aligned}
& \sigma\left(S_{.}\right)=\sigma\left(S_{.}\right)=\sqrt{\frac{5}{48} \sigma_{\mathrm{W}}^{2}+\sigma_{\mathrm{B}}^{2}}=\sqrt{\sigma_{\mathrm{T}}^{2}-\frac{15}{48} \sigma_{\mathrm{W}}^{2}} \\
& \sigma(\mathrm{X})=\sigma(\mathrm{Y})=\sqrt{\frac{3}{48} \sigma_{\mathrm{W}}+\sigma_{\mathrm{B}}^{2}}=\sqrt{\sigma_{\mathrm{T}}^{2}-\frac{7}{48} \sigma_{\mathrm{W}}^{2}}
\end{aligned}
$$

The value for the drift serves as an indicator of possible trouble if it changes markedly from its usual range of values. However, because any linear drift is balanced out, a change in the value does not of itself vitiate the results. 
If the uncertainty attached to the restraint value is not negligible, this will lead to a possible systematic error in all measurements based on this restraint. Therefore, as a bound to this error one should, for the design of section 6 , add to the uncertainty from random error an allowance of one-half the uncertainty in the sum $\left(S .+S_{.}\right)$. This is shown in the computer example.

\section{Computer Program}

Appendix C lists a computer program in BASIC for carrying out the calculation for the gage block example. The program can be used with any design provided one has the arrays of coefficients for the determination of the values of the unknowns and the deviations corresponding to the two arrays given in Section 8 for the gage block example.

The program calls for input of:

a) Administrative data--designation of blocks, operator, date, etc.

b) Process parameters--standard deviations, value for check standard, etc.

c) Comparator readings

The computer programs provide in the output:

a) Deviations, s.d.

b) Values for unknowns, drift, and associated undertainties.

c) Statistical tests as to whether process can be regarded as "in control": on standard deviation and on value of check standard. 


\section{Other Designs for Elimination of Drift With Order of Measurement}

The number of observations over which a linear drift could be expected to be valid varies with the type of measurement, but experience indicates that it is unusual if it is as large as 20. For all distinct pairings of $n$ items $n(n-1) / 2$ exceeds 20 for $n \geq 7$. The table below gives designs for $\mathrm{n}=5,6,7$ which are balanced for linear drift.

$$
\mathrm{n}=5
$$

10 Observations

$$
\begin{aligned}
& +-000 \text { 1-2 } \\
& 0+-002-3 \\
& 00+-0 \text { 3-4 } \\
& 000+-4-5 \\
& \text { - } 000+5-1 \\
& \text { - } 00+0 \text { 4-1 } \\
& 0+0-0 \text { 2-4 } \\
& 0-00+5-2 \\
& 00+0-3-5 \\
& +0-00 \text { 1-3 }
\end{aligned}
$$

$$
n=6
$$

18 Observations

$$
\begin{array}{lllllll}
+ & - & 0 & 0 & 0 & 0 & 1-2 \\
0+ & - & 0 & 0 & 0 & 2-3 \\
0 & 0 & + & - & 0 & 0 & 3-4 \\
0 & 0 & 0 & + & 0 & - & 4-6 \\
0 & 0 & 0 & 0 & - & + & 6-5 \\
- & 0 & 0 & 0 & + & 0 & 5-1
\end{array}
$$$$
00+00-3-6
$$$$
\text { - } 00+00 \text { 4-1 }
$$$$
0+00-0 \text { 2-5 }
$$$$
00-00+6-3
$$$$
+00-00 \text { 1-4 }
$$$$
0-00+0 \text { 5-2 }
$$$$
000-+0 \text { 5-4 }
$$$$
00-00+6-3
$$$$
0-0+00 \text { 4-2 }
$$$$
\text { - } 0+000 \text { 3-1 }
$$$$
0+00-0 \text { 2-5 }
$$$$
+0000-1-6
$$

$$
\mathrm{n}=7
$$

\section{Observations}

$$
\begin{array}{cccccccc}
+ & - & 0 & 0 & 0 & 0 & 0 & 1-2 \\
0 & + & - & 0 & 0 & 0 & 0 & 2-3 \\
0 & 0 & + & - & 0 & 0 & 0 & 3-4 \\
0 & 0 & 0 & + & - & 0 & 0 & 4-5 \\
0 & 0 & 0 & 0 & + & - & 0 & 5-6 \\
0 & 0 & 0 & 0 & 0 & + & - & 6-7 \\
- & 0 & 0 & 0 & 0 & 0 & + & 7-1
\end{array}
$$

$0+0-000$ 2-4

$00+0-003-5$

$000+0-0$ 4-6

$0000+0-5-7$

- $00000+0$ 6-1

$0-0000+7-2$

$+0-00001-3$

$00-000+7-3$

$0-000+0$ 6-2

- $000+00$ 5-1

$000+00-4-7$

$00+00-0$ 3-6

$0+00-00$ 2-5

$+00-0001-4$

An alternate form of displaying the design is shown for $\mathrm{n}=5$ and is used for the other designs. 
Designs that involve a subset of all possible pairings are given below:

$\mathrm{n}=6$

12 Observ.

1-2

5-1

2-3

4-6

3-4

6-5

2-4

$4-5$

6-2

3-1

1-6

5-3 $\mathrm{n}=7$

14 Observ.

1-2

2-3

3-4

4-5

5-6

6-7

7-1

3-1

5-3

7-5

2-7

4-2

6-4

1-6 $\mathrm{n}=8$

16 Observ.

1-2

2-3

3-4

4-5

5-6

6-7

7-8

8-1

4-1

7-4

2-7

5-2

8-5

3-8

6-3

1-6 $\mathrm{n}=9$

18 Observ.

1-2

2-3

6-5

3-1

5-4

8-9

4-7

9-6

7-8

7-1

4-6

9-7

1-4

3-9

5-8

6-3

2-5

8-2 
1. Bose, R. C. \& Cameron, J. M., The Bridge Tournament Problem and Calibration Designs for Comparing Pairs of Objects, NBS J. of Res. $69 B(1965), 323-332$.

2. Eisenhart, C., Realistic Evaluation of the Precision and Accuracy of Instrument Calibration Systems, NBS J. of Res.67C (1963), 161-187.

3. Swindells, J. F., Calibration of Liquid-in-Glass Thermometers, NBS Monograph 90, GPO, 1965.

4. Zelen, M., Linear Estimation and Related Topics, Chapter 17 of Survey of Numerical Analysis edited by J. Todd, McGraw Hill, New York City (1962), 558-584. 
Liquid in glass thermometers are calibrated at NBS in a controlled bath in which the temperature is increasing in a nearly linear fashion with time. The temperature of the bath is measured by platinum resistance thermometry at the beginning, middle, and end of a run with the test thermometers being read once in the first interval and again in reverse order in the second interval. The time sequence for the resistance measurements, $R_{1}, R_{2}, R_{3}$ and the two series of thermometer values denoted by $T_{1}^{\prime}$ and $T_{i}$ are as follows:

$$
\mathrm{R}_{1} \mathrm{~T}_{1}^{\prime} \mathrm{T}_{2}^{\prime} \cdot \cdots \mathrm{T}_{k}^{\prime} \mathrm{R}_{2} \mathrm{~T}_{k} \cdots \mathrm{T}_{2} \mathrm{~T}_{1} \mathrm{R}_{3}
$$

with uniform time intervals between the thermometer readings. Figure shows a schematic of the situation with the increment to the bath temperature being $\Delta$ for each time period except for the middle reading involving resistance thermometry where a step of $\alpha$ in temperature is assumed.

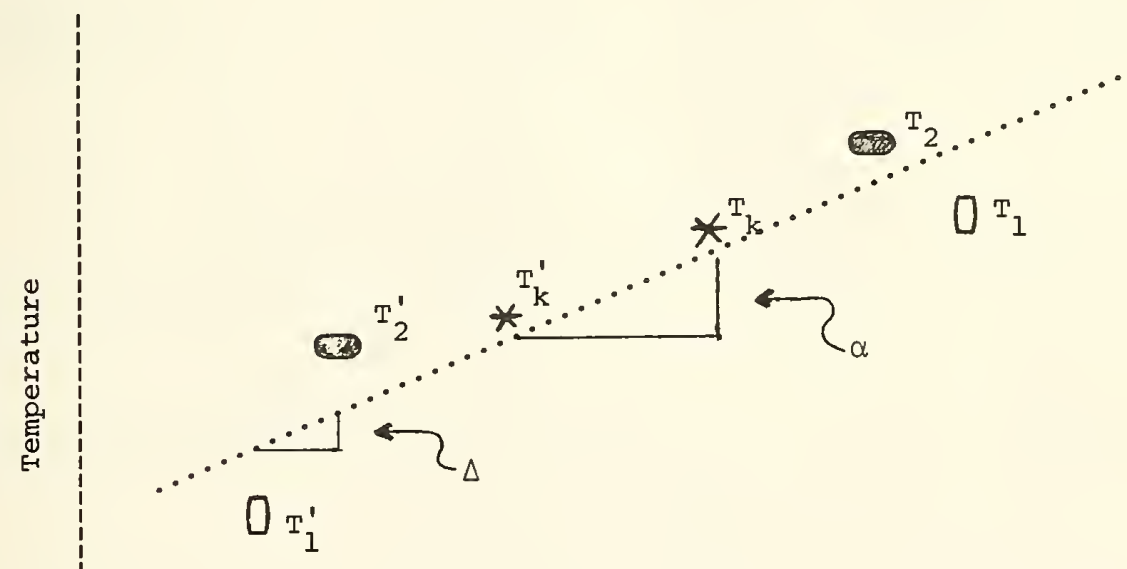

$(\mathrm{k}-1)$ intervals

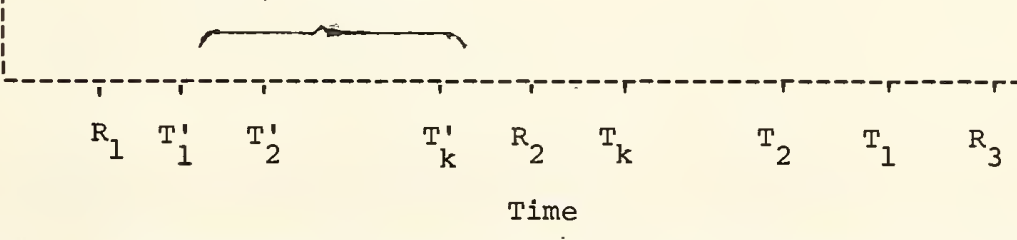

Figure Thermometer reading at fixed time intervals in a bath with linear drift. 
The average $\left(T_{i}+T_{i}\right) / 2$ will be the indication of the $i-t h$ thermometer at the temperature implied by $\left(R_{1}+R_{2}+R_{3}\right) / 3$. The differences, $d_{i}=$ $\mathrm{T}_{i}-\mathrm{T}_{1}^{\prime}$ will be a measure of $\alpha+2(\mathrm{k}-\mathrm{i}) \Delta$ so that the observational equations may be written

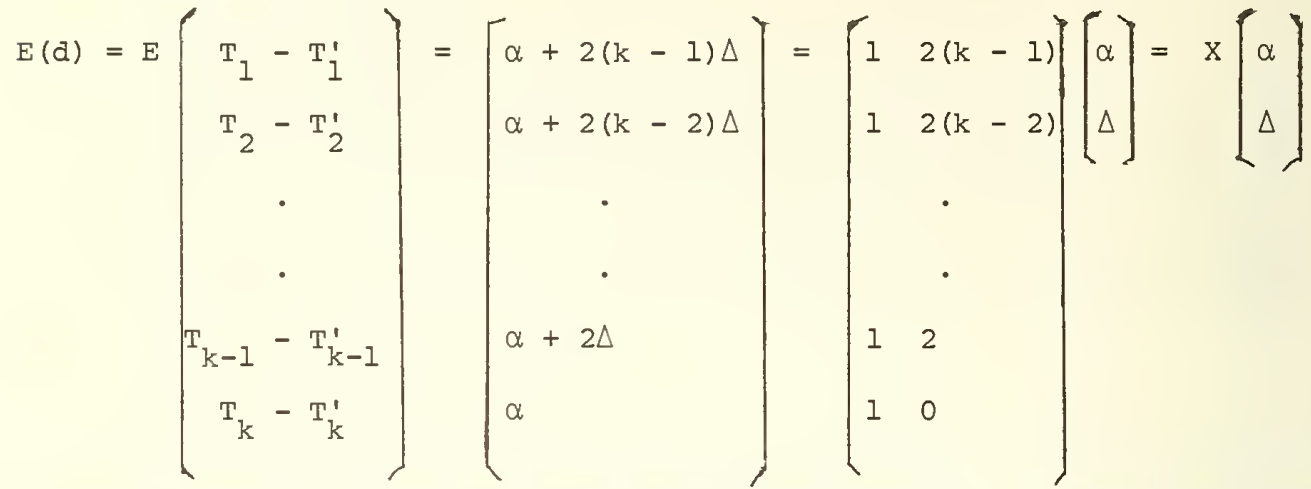
where $\mathrm{X}$ stands for the indicated matrix, and where $\mathrm{E(})$ stands for the "expected value of," $i . e .$, the limiting value if the effects of random error were eliminated.

The least squares estimates of $\alpha$ and $\Delta$ are given by the solution to the normal equations

$$
\left(x^{\prime} x\right)\left[\begin{array}{l}
\alpha \\
\Delta
\end{array}\right]=x^{i} \mathrm{~d}=\left(\begin{array}{ll}
\sum \mathrm{d} & \\
2 \sum \mathrm{d} & (\mathrm{k}-\mathrm{i})
\end{array}\right)
$$

where the inverse of the matrix of normal equations is

$$
\left(X^{\prime} X\right)^{-1}=\left[\begin{array}{ll}
k & k(k-1) \\
k(k-1) & 2 k(k-1)(2 k-1) / 3
\end{array}\right]^{-1}=\frac{1}{k\left(k^{2}-1\right)}\left[\begin{array}{lc}
2(k-1)(2 k-1) & -3(k-1) \\
-3(k-1) & 3
\end{array}\right]
$$

The estimates of $\alpha, \Delta$ and $\sigma^{2}$, the variance of the observations are given by

$$
\begin{gathered}
\hat{\alpha}=\frac{2}{\mathrm{k}(\mathrm{k}+1)}\left[3 \sum i d-(\mathrm{k}+1) \sum \mathrm{d}\right] \\
\hat{\Delta}=\frac{3}{\mathrm{k}\left(\mathrm{k}^{2}-1\right)}\left[(\mathrm{k}+1) \Sigma \mathrm{d}-2 \sum \mathrm{id}\right] \\
\hat{\sigma}^{2}=\frac{1}{\mathrm{k}-2}\left[\sum \mathrm{d}^{2}-\hat{\alpha} \Sigma \mathrm{d}-2 \hat{\Delta} \Sigma(\mathrm{k}-\mathrm{i}) \mathrm{d}\right]=\frac{1}{\mathrm{k}-2} \sum(\mathrm{dev})^{2}
\end{gathered}
$$

where $\mathrm{dev}_{i}=\mathrm{d}_{i}-\hat{\alpha}-2(\mathrm{k}-\mathrm{i}) \hat{\Delta}$.

The standard deviation of the value for the test thermometer is $\sigma / \sqrt{ } 2$ and for $\alpha$ and $\Delta$, 


$$
\begin{aligned}
& \text { s.d. }(\alpha)=\sigma \sqrt{ } 2(2 k-1) / k(k+1) \\
& \text { s.d. }(\Delta)=\sigma \sqrt{ } 3 / k\left(k^{2}-1\right)
\end{aligned}
$$

Control on the measurement process is maintained by two forms of redundancy--one to check on the process average and the other to check on process variability. The first of these is provided by incorporating an NBS standard thermometer among the $k$ thermometers and requiring that its value be within random error of its accepted value. The variability check is given by comparing $\hat{\sigma}$ with the long run value established for the process. When these conditions are satisfied, then one can regard the process as being in a state of control.

A typical set of data for this type of calibration is given in the following table. For simplicity the resistance measurements have been suppressed and the temperature reported directly.

\section{Calibration of Thermometers}

Data From NBS Calibration of 22 August 1972

Provided by J. Wise, NBS, Thermometry Section

\begin{tabular}{|c|c|c|}
\hline$\frac{\text { Observation }}{39.9378}$ & Averages & Correction at $40^{\circ}$ \\
\hline 39.983 & $\mathrm{~T}_{1} \quad 39.9870$ & -0.0436 \\
\hline 39.913 & $\mathrm{~T}_{2} \quad 39.9150$ & 0.0284 \\
\hline 39.966 & $\mathrm{~T}_{3} \quad 39.9675$ & -0.0241 \\
\hline 39.840 & $\mathrm{~T}_{4} \quad 39.8410$ & 0.1024 * \\
\hline
\end{tabular}

Thermometer
Reference (PRT)
Reference (PRT)
$\mathrm{T}_{2}^{\prime}$
$\mathrm{T}_{3}^{\prime}$
$\mathrm{T}_{4}^{\prime}$ (check standard)
$\mathrm{T}_{3}$
$\mathrm{~T}_{2}$
$\mathrm{~T}_{1}$

39.9422 PRT 39.9434

39.842

39.969

39.917

39.991

*accepted value is 0.1000

Reference PRT

39.9501

$$
\begin{array}{rrrrlrr}
\text { i } & \begin{array}{c}
\mathrm{d}= \\
\mathrm{T}_{i}-\mathrm{T}_{i}
\end{array} & \underline{\alpha} & \underline{\Delta} & & \begin{array}{c}
\text { Predicted } \\
\mathrm{d}
\end{array} & \text { dev. } \\
1 & -0.008 & 1 & 6 & \sum \mathrm{d}=-0.077 & -0.0071 & -0.0009 \\
2 & -0.004 & 1 & 4 & \sum i d=-0.033 & -0.0052 & 0.0012 \\
3 & -0.003 & 1 & 2 & 2 / \mathrm{k}(\mathrm{k}+1)=1 / 10 & -0.0033 & 0.0003 \\
4 & -0.002 & 1 & 0 & 3 / \mathrm{k}\left(\mathrm{k}^{2}-1\right)=1 / 20 & -0.0014 & -0.0006 \\
& & & & & \sum \mathrm{dev}^{2}=0.00000270
\end{array}
$$

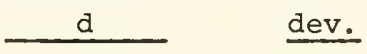




$$
\begin{gathered}
\hat{\alpha}=\frac{1}{10}[3(-0.033)-5(-0.017)]=-0.00140 \\
\hat{\Delta}=\frac{1}{20}[5(-0.017)-2(-0.033)]=-0.00095 \\
\hat{\sigma}=\sqrt{ } \Sigma \mathrm{dev}^{2} / 2=\sqrt{ } 0.00000135=0.00115
\end{gathered}
$$

s.d. $(\hat{\alpha})=\sigma \sqrt{ } \frac{7}{10} \quad$ s.d. $($ average $T)=\sigma / \sqrt{ } 2$

s.d. $(\hat{\Delta})=\sigma \sqrt{ } \frac{1}{20}$ 


\section{Least Squares Analysis of Calibration Designs}

In this appendix the least squares analysis is presented in matrix form for those wishing to prepare a general analysis. Each formal statement will be illustrated by its application to the calibration design of Section 6 .

It is assumed that the expected value of the observations represented in vector form as $\mathrm{y}^{\prime}=\left(\mathrm{y}_{1} \mathrm{y}_{2}\right.$. . . $\left.\mathrm{y}_{\mathrm{n}}\right)$ have expected values $\mathrm{E}(\mathrm{y})=\mathrm{x} \beta$ where $B$ is the vector of parameters and $X$ is the design matrix. It is also assumed that the errors of measurement are uncorrelated and have equal variance, i.e., $V(y)=\sigma^{2} I$.

For the design of section 5 ,

$$
X=\left[\begin{array}{rrrrr}
1 & -1 & 0 & 0 & -7 \\
-1 & 0 & 0 & 1 & -5 \\
0 & 0 & 1 & -1 & -3 \\
0 & 1 & -1 & 0 & -1 \\
0 & 1 & 0 & -1 & 1 \\
-1 & 0 & 0 & 1 & 3
\end{array}\right) \quad B=\left(\begin{array}{l}
A \\
B \\
C \\
D \\
\Delta
\end{array}\right)
$$

The matrix of normal equations is given by $\left(x^{\prime} x\right) \beta=x^{\prime} y$ which for calibration designs is not of full rank.

$$
X^{\prime} X \beta=\left[\begin{array}{ccccc}
4 & -1 & -1 & -2 & 0 \\
-1 & 4 & -2 & -1 & 0 \\
-1 & -2 & 4 & -1 & 0 \\
-2 & -1 & -1 & 4 & 0 \\
0 & 0 & 0 & 0 & 168
\end{array}\right] B=X^{\prime} Y=\left[\begin{array}{rrrrrrrr}
1 & -1 & 0 & 0 & 0 & -1 & 1 & 0 \\
-1 & 0 & 0 & 1 & 1 & 0 & 0 & -1 \\
0 & 0 & 1 & -1 & 0 & 0 & -1 & 1 \\
0 & 1 & -1 & 0 & -1 & 1 & 0 & 0 \\
-7 & -5 & -3 & -1 & 1 & 3 & 5 & 7
\end{array}\right] y^{-1}
$$

In order to solve this system, a restraint in the form $h^{\prime} \beta=K$ is imposed leading to the augmented equations (see Zelen [ 4 ]), 


$$
\left(\begin{array}{cc}
x^{\prime} x & h \\
h^{\prime} & 0
\end{array}\right]\left[\begin{array}{l}
B \\
\lambda
\end{array}\right]=\left[\begin{array}{l}
x^{\prime} y \\
k
\end{array}\right]
$$

For the design as used in the calibration of gage blocks the restraint is that $A+B=K$, giving $h^{\prime}=\left(\begin{array}{lllll}1 & 1 & 0 & 0 & 0\end{array}\right)$ and the augmented equations are

$$
\left(\begin{array}{cccccc}
4 & -1 & -1 & -2 & 0 & 1 \\
-1 & 4 & -2 & -1 & 0 & 1 \\
-1 & -2 & 4 & -1 & 0 & 0 \\
-2 & -1 & -1 & 4 & 0 & 0 \\
0 & 0 & 0 & 0 & 168 & 0 \\
1 & 1 & 0 & 0 & 0 & 0
\end{array}\right) \quad B=\left(\begin{array}{c}
x^{\prime} y \\
K
\end{array}\right)
$$

The solution for the parameter values $\hat{B}$ are

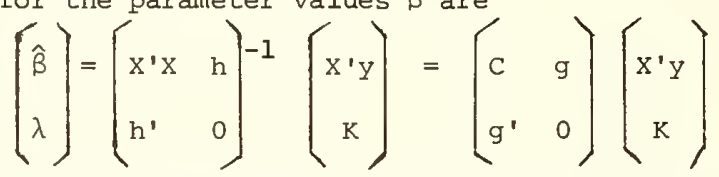

where $\mathrm{C}$ is the indicated $\mathrm{KxK}$ matrix arising in the inversion process $\mathrm{n}$. For the example

$$
(\hat{B})=\frac{1}{336}\left(\begin{array}{rrrrrr}
35 & -35 & -7 & 7 & 0 & 168 \\
-35 & 35 & 7 & -7 & 0 & 168 \\
-7 & 7 & 91 & 21 & 0 & 168 \\
7 & -7 & 21 & 91 & 0 & 168 \\
0 & 0 & 0 & 0 & 2 & 0 \\
168 & 168 & 168 & 168 & 0 & 0
\end{array}\right)\left(\begin{array}{l}
X^{\prime} Y \\
K
\end{array}\right]=\frac{1}{168}\left(\begin{array}{rrrrrrrrr}
35 & -14 & -7 & -14 & -21 & -14 & 21 & 14 & 84 \\
-35 & 14 & 7 & 14 & 21 & 14 & -21 & -14 & 84 \\
-7 & 14 & 35 & -42 & -7 & 14 & -49 & 42 & 84 \\
7 & 42 & -35 & -14 & -49 & 42 & -7 & 14 & 84 \\
-7 & -5 & -3 & -1 & 1 & 3 & 5 & 7 & 0 \\
0 & 0 & 0 & 0 & 0 & 0 & 0 & 0 & 0
\end{array}\right)\left(\begin{array}{l}
Y \\
K
\end{array}\right)
$$

$$
\text { for which } C=\frac{1}{336}\left(\begin{array}{rrrrr}
35 & -35 & -7 & 7 & 0 \\
-35 & 35 & 7 & -7 & 0 \\
-7 & 7 & 91 & 21 & 0 \\
7 & -7 & 21 & 91 & 0 \\
2 & 0 & 0 & 0 & 2
\end{array}\right)
$$


The variances of the parameters are given by $c_{i i} \sigma^{2}$ and of Iinear functions, $\ell \cdot \beta$, the variance is $\ell^{\prime} C l \sigma^{2}$. For the example

$$
\begin{aligned}
& \mathrm{V}(\hat{\mathrm{A}})=\mathrm{V}(\hat{\mathrm{B}})=\mathrm{C}_{11} \sigma^{2}=\mathrm{C}_{22} \sigma^{2}=35 \sigma^{2} / 336=5 \sigma^{2} / 48 \\
& \mathrm{~V}(\hat{\mathrm{C}})=\mathrm{V}(\hat{\mathrm{D}})=\mathrm{C}_{33} \sigma^{2}=\mathrm{C}_{44} \sigma^{2}=91 \sigma^{2} / 336=13 \sigma^{2} / 48 \\
& \mathrm{~V}(\hat{\mathrm{A}-\mathrm{B}})=\left(\mathrm{C}_{11}+\mathrm{C}_{22}-2 \mathrm{C}_{12}\right) \sigma^{2}=140 \sigma^{2} / 336=5 \sigma^{2} / 12 \\
& \mathrm{~V}(\hat{\mathrm{A}+\mathrm{B}})=0 \\
& \mathrm{~V}(\hat{\mathrm{C}+\mathrm{D}})=\left(\mathrm{C}_{33}+\mathrm{C}_{44}+2 \mathrm{C}_{34}\right) \sigma^{2}=224 \sigma^{2} / 336=2 \sigma^{2} / 3 \\
& \mathrm{~V}(\hat{\mathrm{C}-\mathrm{D}})=\left(\mathrm{C}_{33}+\mathrm{C}_{44}-2 \mathrm{C}_{34}\right) \sigma^{2}=140 \sigma^{2} / 336=5 \sigma^{2} / 24 \\
& \mathrm{~V}(\hat{\Delta})=\mathrm{C}_{55} \sigma^{2}=2 \sigma^{2} / 336=\sigma^{2} / 168
\end{aligned}
$$


If one had assigned the two standards to positions $B$ and $C$ instead of to $A$ and $B$ as was done, then one would be repeating the measurement of the difference $(B-C)$, and of the difference ( $A-D)$. These differences are internal to the pair of standards over the pair of unknowns and one might suspect that they add little to the transfer from standard to test item. This is confirmed by examination of the inverse of the matrix of normal equations,

$$
\left[\begin{array}{cccccc}
4 & -1 & -1 & -2 & 0 & 0 \\
-1 & 4 & -2 & -1 & 0 & 1 \\
-1 & -2 & 4 & -1 & 0 & 1 \\
-2 & -1 & -1 & -14 & 0 & 0 \\
0 & 0 & 0 & 0 & 168 & 0 \\
0 & 1 & 1 & 0 & 0 & 0
\end{array}\right)^{-1}=\frac{1}{168}\left(\begin{array}{rrrrrr}
56 & 0 & 0 & 28 & 0 & 84 \\
0 & 14 & -14 & 0 & 0 & 84 \\
0 & -14 & 14 & 0 & 0 & 84 \\
28 & 0 & 0 & 56 & 0 & 84 \\
0 & 0 & 0 & 0 & 1 & 0 \\
84 & 84 & 84 & 84 & 0 & 0
\end{array}\right]
$$

The variances for the standards are

$$
\begin{gathered}
\mathrm{V}(\hat{\mathrm{B}})=\mathrm{V}(\hat{\mathrm{C}})=14 \sigma^{2} / 168=\sigma^{2} / 12 \\
\mathrm{~V}(\hat{\mathrm{B}-\mathrm{C}})=56 \sigma^{2} / 168=\sigma^{2} / 3
\end{gathered}
$$

which is smaller than for the restraint $A+B=K$.

However, for the test items the variances are

$$
V(\hat{A})=V(\hat{D})=56 \sigma^{2} / 168=\sigma^{2} / 3
$$

which is larger than that with the restraint $A+B=K$ for which the corresponding variance is $13 \sigma^{2} / 48$.

The estimate for the test item, A, is

$$
\hat{A}=\frac{1}{24}\left[8 y_{1}-4 y_{2}-4 y_{3}-4 y_{5}-4 y_{6}+8 y_{7}\right]+\frac{K}{2}
$$

which does not involve $y_{4}$ and $y_{8}$ which are measurements of the difference between the two standards, i.e., of B-C. Thus, there is a gain in efficiency in the calibration of the test block by using positions $A$ and $B$ for the standards, the efficiency factor being $\left(\sigma^{2} / 3\right) /\left(13 \sigma^{2} / 48\right)=16 / 13$. 
If there were but a single standard, $A$, the inverse of the matrix of normal equations would be

$$
\left[\begin{array}{rrrrrr}
4 & -1 & -1 & -2 & 0 & 1 \\
-1 & 4 & -2 & -1 & 0 & 0 \\
-1 & -2 & 4 & -1 & 0 & 0 \\
-2 & -1 & -1 & 4 & 0 & 0 \\
0 & 0 & 0 & 0 & 168 & 0 \\
1 & 0 & 0 & 0 & 0 & 0
\end{array}\right]-1=\frac{1}{168}\left[\begin{array}{rrrrrr}
0 & 0 & 0 & 0 & 0 & 168 \\
0 & 70 & 42 & 28 & 0 & 168 \\
0 & 42 & 70 & 28 & 0 & 168 \\
0 & 28 & 28 & 56 & 0 & 168 \\
0 & 0 & 0 & 0 & 1 & 0 \\
168 & 168 & 168 & 168 & 0 & 0
\end{array}\right]
$$

The variances of the test items are

$$
\begin{gathered}
\mathrm{V}(\hat{\mathrm{B}})=\mathrm{V}(\hat{\mathrm{C}})=70 \sigma^{2} / 168=5 \sigma^{2} / 12 \\
\mathrm{~V}(\hat{\mathrm{D}})=56 \sigma^{2} / 168=\sigma^{2} / 3
\end{gathered}
$$

\section{FOOTNOTE 3}

If the sum of all four were taken as the restraint, the inverse of the matrix of normal equations would be

$$
\left[\begin{array}{rrrrrr}
4 & -1 & -1 & -2 & 0 & 1 \\
-1 & 4 & -2 & -1 & 0 & 1 \\
-1 & -2 & 4 & -1 & 0 & 1 \\
-2 & -1 & -1 & 4 & 0 & 1 \\
0 & 0 & 0 & 0 & 168 & 0 \\
1 & 1 & 1 & 1 & 0 & 0
\end{array}\right)-1=\frac{1}{336}\left[\begin{array}{rrrrrr}
49 & -21 & -21 & -7 & 0 & 84 \\
-21 & 49 & -7 & -21 & 0 & 84 \\
-21 & -7 & 49 & -21 & 0 & 84 \\
-7 & -21 & -21 & 49 & 0 & 84 \\
0 & 0 & 0 & 0 & 2 & 0 \\
84 & 84 & 84 & 84 & 0 & 0
\end{array}\right]
$$

The variances of all four test items are the same

$$
\mathrm{V}(\hat{\mathrm{A}})=\mathrm{V}(\hat{\mathrm{B}})=\mathrm{V}(\hat{\mathrm{C}})=\mathrm{V}(\hat{\mathrm{D}})=49 \sigma^{2} / 336=7 \sigma^{2} / 48
$$




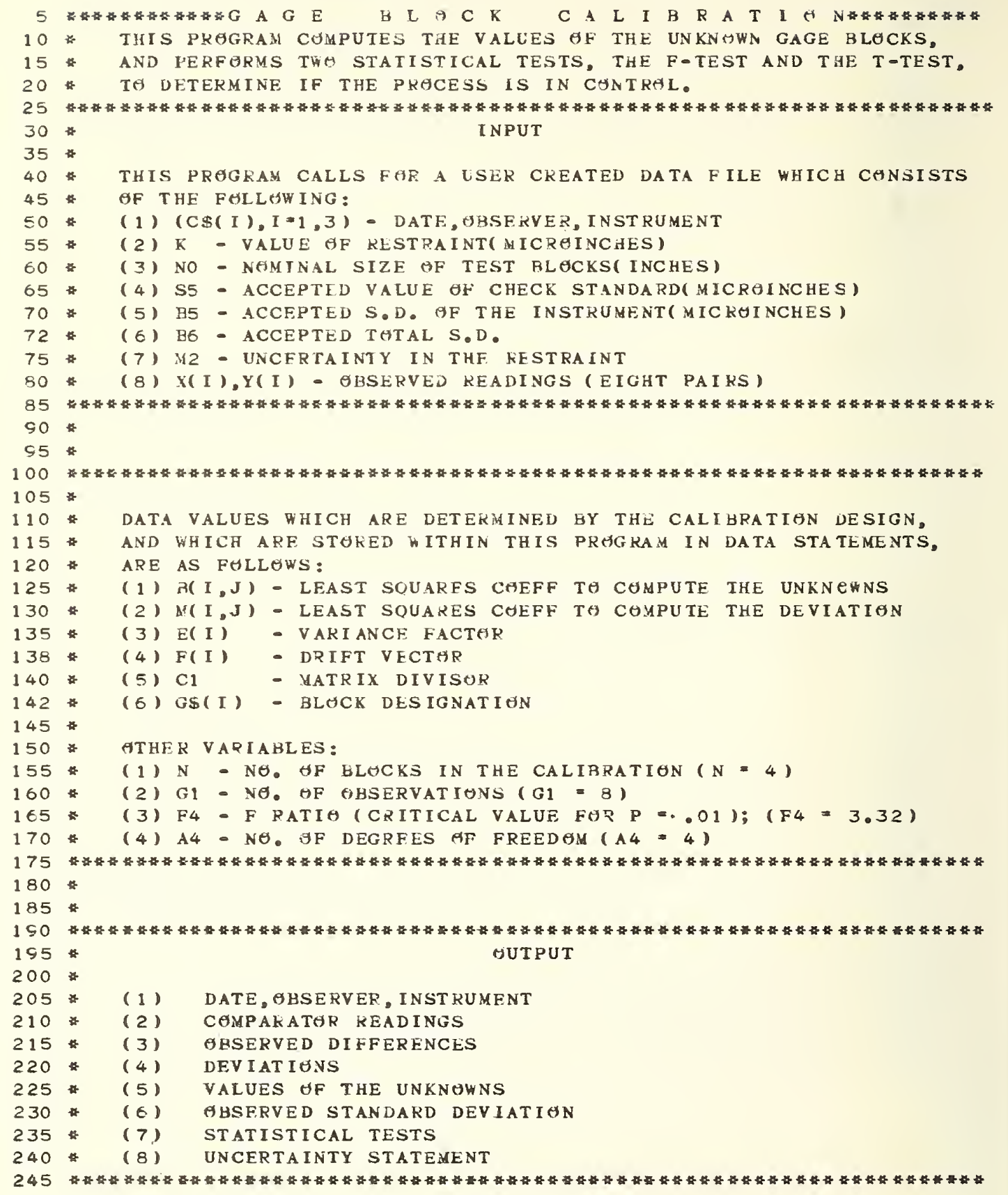


$250 \mathrm{DIM} \operatorname{Cs}(3), B(4,9), M(8,8), A(9), X(8), Y(8), G \$(4)$

255 DATA $35,-14,-7,-14,-21,-14,21,14,84$

$2 \in O$ DATA $-35,14,7,14,21,14,-21,-14,84$

265 DATA $-7,14,35,-42,-7,14,-49,42,84$

270 DATA $7,42,-35,-14,-49,42,-7,14,84$

275 DATA $49,-7,-7,21,49,49,-7,21$

280 DATA $-7,87,13,-5,33,-41,53,35$

285 DATA $-7,13,89,25,-39,37,57,-7$

290 DATA $21,-5,25,111,-27,3,-23,63$

295 DATA $49,33,-39,-27,97,25,9,21$

300 DATA $49,-41,37,3,25,103,13,-21$

305 DATA $-7,53,57,-23,9,13,73,-7$

310 DATA $21,35,-7,63,21,-21,-7,63$

312 DATA $-7,-5,-3,-1,1,3,5,7$

315 DATA $.31250,031250,0145833,0145833$

320 DATA 168

322 DATA S,. S.., X, Y

$330 \mathrm{~N}=4$

$335 \mathrm{G} 1=8$

$340 \quad F 4=3.32$.

$345 \quad A 4=4$

$350 R 1=G 1+1$

355 * REA CAEFFICIENTS USED TA Compute VAlues of the blecks

$360 \mathrm{FAR} I=1, \mathrm{~N}$

365 FAR J1 = 1, R1

$370 \operatorname{READ} B(I, J 1)$

375 NEXT J1

380 NEXT I

385 * READ COFFFICIENTS USED TO CAMPUTE THE DEVIATIONS

390 FOR I $=1, \mathrm{GI}$

395 FER J1 $=1, G 1$

400 READ M(I,J1)

405 NEXT J 1

410 NEXT I

411 * READ DRIFT VECTUR

$412 \mathrm{~F} \theta \mathrm{R} I=1, \mathrm{G} 1$

413 READ F(I)

414 NEX T I

415 * READ VARIANCF VECTOR

420 FQR $I=1, N$

425 READ E(I)

430 NEXT I

435 READ MATRIX DIYIS SRR

440 READ C1

441 * READ BLOCK DESIGNATIONS

442 FGR I $=1, \mathrm{~N}$

443 READ GS( I)

444 NEXT I 
445 * DEPINE USER DATA FILE - DATA 1

450 FILES DATA 1

455 READ ADMINISTRATIVE DATA AND PRGCESS PARAMETERS

460 READ\#1, $\operatorname{Cs}(1), \operatorname{CS}(2), \operatorname{CS}(3)$

$465 \mathrm{READ} * 1, \mathrm{~K}, \mathrm{NO}, \mathrm{S} 5, \mathrm{B5}, \mathrm{B6}, \mathrm{M2}$

470 \# READ CAMPARATAR READINGS AND COMPUTE THEIR DIFFERENCES

471 * ALSO, CEMPUTE DRIFT = D1, AND S.D.(DRIFT) = S1

$473 \quad \mathrm{DI}=0$

475 FAR I $=1, G 1$

480 READ\#1, X( I ), Y ( I)

$485 A(I)=X(I)-Y(I)$

$487 \mathrm{D1}=\mathrm{D} 1+\mathrm{A}(\mathrm{I}) * \mathrm{~F}(\mathrm{I})$

490 NEXT I

$492 \mathrm{D} 1=\mathrm{D} 1 / \mathrm{C} 1$

$493 \mathrm{S1}=\mathrm{B} 5 *(1 . / \mathrm{Cl}) \uparrow .5$

495 SET A $(9)=$ RESTRAINT

$500 \quad A(9)=K$

505 * COMPUTE VALUES = V(I), S. D. = Z(I), AND UNCERTAINTY = C(I)

510 FOR I $=1, \mathrm{~N}$

$515 \quad \mathrm{Y} 1=0$

520 FबR $J_{1}=1, R 1$

$525 \mathrm{Y} 1=\mathrm{Y} 1 \cdot \mathrm{B}(\mathrm{I}, \mathrm{J} 1) \times \mathrm{A}(\mathrm{J} 1)$

530 NEXT J 1

$535 \mathrm{~V}(\mathrm{I})=\mathrm{Y} 1 / \mathrm{Cl}$

$540 Z(I)=(B 6 \uparrow 2-B 5 \uparrow 2 * E(I)) .5$

$545 \mathrm{C}(\mathrm{I})=3 * \mathrm{Z}(\mathrm{I}) * .5 * \mathrm{M} 2$

550 NEXT I

555 * COMPUTE CHECK STANDARD

$560 \quad C 5=V(1)-V(2)$

565 COMPUTE THE DEVIATIGNS AND THE OBSERVED S.D.

570 SO $=0$

575 FAR I $=1, G_{1}$

$580 \quad \mathrm{DO}=0$

585 F $8 R \quad J 1=1, G 1$

$590 D O=D O+M\left(I, J_{1}\right) * A\left(J_{1}\right)$

595 NEXT J 1

$600 \mathrm{D}(\mathrm{I})=\mathrm{DO} / \mathrm{Cl}$

$605 \mathrm{SO}=\mathrm{SO}+\mathrm{D}($ I $) \uparrow 2$

610 NEXT I

$615 \mathrm{~S}=(\mathrm{S} 0 / \mathrm{A} 4) \uparrow .5$

620 PERFARM STATISTICAL TESTS

$625 \mathrm{~F}=(\mathrm{S} / \mathrm{B5}) \uparrow_{2}$

$630 \mathrm{~T}=(\mathrm{C} 5-\mathrm{S} 5) / \mathrm{B} 6$ 


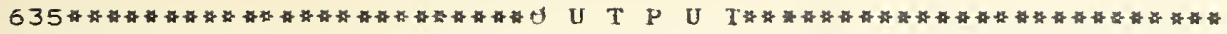

640 PRI NT, 906

645 PRINT DATE, CS(1)

650 PRINT OHS., C\$( 2$)$

655 PRINT INSTR., CS( 3 )

660 PRINT, 905

665 PRINT GBSERVATIONS

670 FER $I=1, G 1$

675 PRINT X(I), Y(I)

680 NEXT I

685 PRINT SBSERVED DIFFERENCES AND DFVIATIONS

690 PRINT,695

695 FMT $/ 1, X 18, A(I), X 8$, DEV( I )

$700 \mathrm{FHR} I=1, \mathrm{~F} 1$

705 PRINT,710,A( I ), D( I )

710 FMT X14, FC. 3, X4, F9.3

715 NEXT I

720 *RINT VALUES GF THE BLGCKS

722 PRINT, 723

$723 \mathrm{FMT} / /, \mathrm{X} 58$, UNCERTAINTY

725 PRINT, 730

730 FMT X19, NHM.,X8, CURR, X10,S, D., X4,3(S.D.) . 5(S.E.)

735 FEIR I $=1, N$

740 PRIN I, 745, Gs ( I ), NO, V(I ), Z( I ), C( I )

745 FNT F12.6,F11.2, X7, $18.5, F 15.5$

750 NEXT I

755 PRINT STATISTICAL INFERMATION

760 PR I N T, 765

765 PRINT \&HS. S. D,ACC, S.D.,F TEST,F RATI , D.F.

770 PRINT,775, S, B5, F, F4, A4

775 FMT F7.4,X5,F9.5,X3,F8.3, F12.2, I 10

780 IF F>F4 THEN 790

785 GA TA 800

790 PRI N T, 795

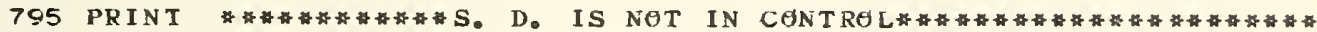

800 PRINT, 805

805 PRINT ABS. CHECK, ACC, CHECK, T TEST

810 PRIN T, 815, C5, S5, T

815 FNT F10.5,F11.5,F12.5

820 IF ABS(T) > 3 THFN 830

$825 \mathrm{GH} T \mathrm{TH} 840$

830 PRINT, 835

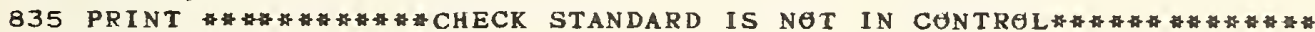

840 PRINT.905

845* PRINT DRIFT AND S.D. (DRIFT)

885 PR INT,890, DI, SI

890 FMT DRI FT

895 PR INT,900,K

$900 \mathrm{FMT} / / /$, RESTRAINT (.$* \mathrm{~S}_{\bullet}$.)

$=, F 10.4 /$ S.D. (DRIFT) $=$ F10.4

901 PRINT, $903, \mathrm{M} 2$

902 PRINT, 906

903 FMT SYSTEMATIC ERRER(S.E.) IN RESTRAINT =.F8.2

905 FMT $/ /$

906 FMT $/ 1 / 1 / 1$

910 STEP

915 END 
10 MAY 281974 , HOWELL, FEDERAL 1

$206.4, .101,0.133, .32, .49, .20$

$3052.0,52.5$

$4045.2,52.1$

$5050.0,45.1$

6053.1 .50 .0

$7052.3,45.2$

8045.1 .52 .0

9052.0 .50 .1

10050.1 .52 .3

\section{OUTPUT}

$\begin{array}{ll}\text { DATE } & \text { MAY 28 } 1974 \\ \text { HES. } & \text { HEWELL } \\ \text { INSTR. } & \text { FEDERAL } 1\end{array}$

ORSERVATIANS

$$
\begin{aligned}
& 52 \\
& 45.2 \\
& 50 \\
& 53 \cdot 1 \\
& 52.3 \\
& 45.1 \\
& 52 \\
& 50.1
\end{aligned}
$$

S.

S.

$\mathbf{X}$

$\mathbf{Y}$

$$
\begin{array}{ll}
52.5 & \\
52.1 & \\
45.1 & \\
50 & \\
45.2 & \\
52 & \\
50.1 & \\
52.3 & \\
1(1) & \\
-.500 & -.029 \\
-6.900 & .113 \\
4.900 & .571 \\
3.100 & -.237 \\
7.100 & -.079 \\
-6.900 & -.154 \\
1.900 & .304 \\
-2.200 &
\end{array}
$$

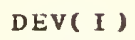

Nब

. 101000

.101000

- 101000

.101000
S. $D$. .45618 .45618 .47452 .47452
UN CE RTA I N T Y 3(S.D.)*.5(S.E.)

1.46854

1. 45854

1. 52355

1. 52355
ABS. S. D
ACC. S. D。
F TEST
. 32000
F RATIO
3.32
D. F .
1. 271
4
ARS. CHECK ACC. СRECK T TEST
$. .50000 \quad-.13300 \quad 0.74898$

$\begin{array}{ll}\text { DRIFT } & =0042 \\ \text { S.D.(DRIFT) }= & .0247\end{array}$




\section{NBS TECHNICAL PUBLICATIONS}

\section{PERIODICALS}

JOURNAL OF RESEARCH reports National Bureau of Standards research and development in physics, mathematics, and chemistry. Comprehensive scientific papers give complete details of the work, including laboratory data, experimental procedures, and theoretical and mathematical analyses. Illustrated with photographs, drawings, and charts. Includes listings of other NBS papers as issued.

Published in two sections, available separateIy:

- Physics and Chemistry (Section A)

Papers of interest primarily to scientists working in these fields. This section covers a broad range of physical and chemical research, with major emphasis on standards of physical measurement, fundamental constants, and properties of matter. Issued six times a year. Annual subscription: Domestic, \$17.00; Foreign, $\$ 21.25$.

- Mathematical Sciences (Section B)

Studies and compilations designed mainly for the mathematician and theoretical physicist. Topics in mathematical statistics, theory of experiment design, numerical analysis, theoretical physics and chemistry, logical design and programming of computers and computer systems. Short numerical tables. Issued quarterly. Annual subscription: Domestic, $\$ 9.00$; Foreign, $\$ 11.25$.

DIMENSIONS/NBS (formerIy Technical News Bulletin)-This monthly magazine is published to inform scientists, engineers, businessmen, industry, teachers, students, and consumers of the latest advances in science and technology, with primary emphasis on the work at NBS.

DIMENSIONS/NBS highlights and reviews such issues as energy research, fire protection, building technology, metric conversion, pollution abatement, health and safety, and consumer product performance. In addition, DIMENSIONS/NBS reports the results of Bureau programs in measurement standards and techniques, properties of matter and materials, engineering standards and services, instrumentation, and automatic data processing.

A nnual subscription: Domestic, $\$ 6.50$; Foreign, $\$ 8.25$.

\section{NONPERIODICALS}

Monographs-Major contributions to the technical literature on various subjects related to the Bureau's scientific and technical activities.

Handbooks-Recommended codes of engineering and industrial practice (including safety codes) developed in cooperation with interested industries, professional organizations, and regulatory bodies.

Special Publications-Include proceedings of high-level national and international conferences sponsored by NBS, precision measurement and calibration volumes, NBS annual reports, and other special publications appropriate to this grouping such as wall charts and bibliographies.

Applied Mathematics Series-Mathematical tables, manuals, and studies of special interest to physicists, engineers, chemists, biologists, mathematicians, computer programmers, and others engaged in scientific and technical work.
NationaI Standard Reference Data Series-Provides quantitative data on the physical and chemical properties of materials, compiled from the world's literature and critically evaluated. Developed under a world-wide program coordinated by NBS. Program under authority of National Standard Data Act (Public Law 90-396). See also Section 1.2.3.

Building Science Series-Disseminates technical information developed at the Bureau on building materials, components, systems, and whole structures. The series presents research results, test methods, and performance criteria related to the structural and environmental functions and the durability and safety characteristics of building elements and systems.

Technical Notes-Studies or reports which are complete in themselves but restrictive in their treatment of a subject. Analogous to monographs but not so comprehensive in scope or definitive in treatment of the subject area. Often serve as a vehicle for final reports of work performed at NBS under the sponsorship of other government agencies.

Voluntary Product Standards-Developed under procedures published by the Department of Commerce in Part 10, Title 15, of the Code of Federal Regulations. The purpose of the standards is to establish nationally recognized requirements for products, and to provide all concerned interests with a basis for common understanding of the characteristics of the products. The National Bureau of Standards administers the Voluntary Product Standards program as a supplement to the activities of the private sector standardizing organizations.

Federal Information Processing Standards Publications (FIPS PUBS)-Publications in this series collectively constitute the Federal Information Processing Standards Register. The purpose of the Register is to serve as the official source of information in the Federal Government regarding standards issued by NBS pursuant to the Federal Property and Administrative Services Act of 1949 as anended, Public Law 89-306 (79 Stat. 1127), and as implemented by Executive Order 11717 (38 FR 12315, dated May 11, 1973) and Part 6 of Title 15 CFR (Code of Federal Regulations). FIPS PUBS will include approved Federal information processing standards information of general interest, and a complete index of relevant standards publications.

Consumer Information Seriea-Practical information, based on NBS research and experience, covering areas of interest to the consumer. Easily understandable language and illustrations provide useful background knowledge for shopping in today's technological marketplace.

NBS Interagency Reports-A special series of interim or final reports on work performed by NBS for outside sponsors (both government and non-government). In general, initial distribution is handled by the sponsor; public distribution is by the National Technical Information Service (Springfield, Va. 22151) in paper copy or microfiche form.

Order NBS publications (except Bibliographic Subscription Services) from: Superintendent of Documents, Government Printing Office, Washington, D.C. 20402.

\section{BIBLIOGRAPHIC SUBSCRIPTION SERVICES}

The following current-awareness and literature-survey bibliographiea are issued periodically by the Bureau:

Cryogenic Data Center Current Awareneas Service (Publications and Reports of Interest in Cryogenics). A literature survey issued weekly. Annual subscription: Domestic, $\$ 20.00$; foreign, $\$ 25.00$.

Liquefied Natural Gas. A literature survey issued quarterly. Annual subscription: $\$ 20.00$.

Superconducting Devices and Materials. A literature aurvey issued quarterly. Annual subscription: $\$ 20,00$. Send subscription orders and remittances for the pre- ceding bibliographic services to the U.S. Department of Commerce, National Technical Information Service, Springfield, Va. 22151.

Electromagnetic Metrology Current Awareneas Service (Abstracts of Selected Articles on Measurement Techniques and Standards of Electromagnetic Quantities from D-C to Millimeter-Wave Frequenciea). Issued monthly. Annual subscription: $\$ 100.00$ (Special rates for multi-subscriptions). Send subscription order and remittance to the Electromagnetic Metrology Information Center, Electromagnetics Division, National Bureau of Standards, Boulder, Colo. 80302. 
National Bureau of Standards

Washington, D.C. 20234

POSTAGE AND FEES PAID

DFFICIAL BUSINESS

Penalty for Private Use, $\$ 300$
U.S. DEPARTMENT DF CDMMERCE $C O M-215$

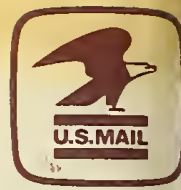

